\title{
Youth and suicide
}

\section{Some basic facts}

Suicide is a major cause of death among youth, second only to motor vehicle crashes in most Western countries. Each year in Canada about 500 teenagers commit suicide. The problem is even worse when one considers that about I2 times as many youth attempt suicide as die from it. Also, youth who survive their first attempt are at increased risk of trying to kill themselves again and are more likely to succeed.

\section{Are you or your family member at risk?}

Studies have shown that more than 90\% of teenagers who try to take their life have a mental health problem such as depression, manic depression, schizophrenia, or severe behavioural or substance abuse problems. Also, these youth often have more than one mental health problem, often try more than once to commit suicide and may have someone in their family who has attempted or committed suicide.

In general, females are twice as likely as males to attempt suicide. Poverty, major family problems such as divorce and a history of child abuse seem to be risk factors associated with suicide attempts. Being gay, lesbian or transgender may also be a risk factor, especially when families and friends do not approve of or accept this type of sexual orientation. Experts are not sure how much each of these factors, alone or in combination, really influence suicidal behaviour.

\section{Warning signs}

- Feeling very depressed or extremely tired or constantly sad

- Feeling hopeless
- Withdrawing from family members and participation in family affairs

- Withdrawing from friends and usual social activities

- Loss of interest in activities once enjoyed

- No longer taking care of appearance (washing, wearing clean clothes, combing hair)

- Persistently putting self down

- Starting or increasing the use of drugs and alcohol

- Thinking and talking about people who have died or committed suicide

- Mentioning suicide or death in conversations, schoolwork or artwork

- Giving away important personal items Simply having any of these warning signs does not mean that the person is thinking of committing suicide. In fact, most people have these feelings or show these signs for short periods at one time or another. However, you should be concerned if these thoughts, feelings or signs last for several days or weeks and are accompanied by major changes in personality or ability to function.

\section{Help for youth at risk for suicide}

Some of the most promising suicide prevention strategies for youth include:

- Screening for depression in schools

- Training teachers and other professionals working with youth how to identify depression and help youth obtain medical care (this approach is called "gatekeeper training")

- Training primary care physicians to recognize and effectively treat depression in youth and, when necessary, refer these patients to specialist mental health practitioners.

\section{Where to get help}

If someone you know speaks to you about committing suicide, makes threats to end his or her life or attempts suicide, he or she should be taken to the closest emergency medical service or to a primary health care provider, such as his or her family doctor or pediatrician. It is important that you provide information about what you have seen or heard to the doctor or nurse conducting the assessment.

If you, your friend or your child is depressed and having difficulties at home or school because of the depression, please see your family doctor, school counsellor or school health nurse for help. Do not wait until things are so bad that suicide seems to be a solution to the problems.

Remember, there are many effective treatments that can help. Reaching out for that help is the first step on the road to recovery.

\section{Where to get more information}

Helpful resources include the Centre for Suicide Prevention (www.suicideinfo .ca), the Canadian Mental Health Association (www.cmha.ca) and the Canadian Red Cross Youth Suicide Prevention website (www.youthsuicide.ca).

\section{Magdalena Szumilas BSc \\ Departments of Community Health and Epidemiology and of Psychiatry Stanley P. Kutcher MD \\ Department of Psychiatry \\ Dalhousie University \\ Halifax, NS}

Competing interests: None declared.

Une version française de cet article est disponible à l'adresse www.cmaj.ca/cgi /content/full/I78/3/286/DCI 